\title{
Poly(ethyleneimine)* Inhibition Effect on Calcium Oxalate Crystallization
}

\author{
George Stefanov Georgiev, Maria Dimitrova Djarova, Bistra Borisova Simeonova, \\ and George Ivanov GeORGIEv \\ Department of Chemistry, University of Sofia, 1, J. Bourchier Avenue, 1126, Sofia, Bulgaria
}

(Received March 25, 1996)

\begin{abstract}
KEY WORDS Induction Period / Inhibition / Inhibitory Efficiency / Crystal Grows Rate / Crystallite Aggragation / Polyhelatogene /
\end{abstract}

Water soluble polymer and polyelectrolyte effect on calcium oxalate $(\mathrm{CO})$ crystalization is of special interest as the latter is a general process of the kidney stone formation. $^{1-4}$ Poly(vinylpyrrolidone) (PVP) and several polyanions have been tested to this end. In our previous work $^{5}$ it was shown more of the poly(acrylic acid-co$N$-vinylpyrrolidone) (CP) inhibition effect than of the PVP and poly(acrylic acid) individually. In the present work the inhibition effect of two polycations $\left(\operatorname{poly}\left(N, N^{\prime}\right.\right.$ dimethylaminoethyl methacrylate), PDMAEM and poly(ethyleneimine)*1 PEI) are verified for the first time. Their comparison with those of PVP and CP with 0.46 acrylic acid monomer part mole fraction (CP-46) is performed also. It is shown the PEI inhibition effect is much more than that of the other polymers.

\section{EXPERIMENTAL}

PEI (BASF) with MW $4 \times 10^{4} \mathrm{Da}$ is used. PDMAEM is synthesized by radical polymerization in water using potassium persulfate as an initiator $(25 \%(\mathrm{w} / \mathrm{v})$ monomer and $0.1 \mathrm{~mol} \%$ initiator about monomer) at $55^{\circ} \mathrm{C}$. The produced polymer is lyophilized after the dialysis of its solutions against water. The methods for $\mathrm{CO}$ preparation, isothermal crystallization, induction period and crystallization rate determination used in this work, have been described in our previous work. ${ }^{5}$ Inhibitory efficiency $(\gamma)$ is calculated using the ratio $\gamma=\left(\tau_{1}-\tau_{0}\right) / \tau_{0}$ where $\tau_{1}$ and $\tau_{0}$ are the induction periods in the presense and absense of the polymer inhibitor, respectively. The degree of crystallization $(\alpha)$ is determined as a ratio $\alpha_{\mathrm{t}}=\left(c_{0}-\mathrm{c}_{\mathrm{t}}\right) /\left(c_{0}-c_{\infty}\right)$ where $c_{0}, c_{\mathrm{t}}$, and $c_{\infty}$ are the CO concentrations at the corresponding moments $(0, \mathrm{t}$, and after a very long time from the crystallization start). $c_{\infty}$ is an equilibrium $\mathrm{CO}$ concentration depending on the temperature, initial $\mathrm{CO}$ concentration and PEI concentration which is used for the determination of the CO supersaturation $S$. The $S$ equality is the condition providing a comparability of the obtained at different temperatures and PEI concentrations results.

\section{RESULTS AND DISCUSSION}

$\tau$ and $\gamma$ values during the $\mathrm{CO}$ crystallization at different temperatures, in the absense of a polymer inhibitor and in the presence of PVP ${ }^{5}, \mathrm{CP}-46^{5}$, PDMAEM, and PEI

* IUPAC Nomenclature: Poly(imino-1,2-ethanediyl). are compared in Table I. A very great CO PEI nucleation retardation effect comes forward. It is more than two order times that of CP-46 which as it was already shown ${ }^{5}$ is the most considerable among the other polymer inhibitors. It is important to note that the large PEI inhibitory efficiency at $50^{\circ} \mathrm{C}$ when those of PVP is absent and those of CP-46 is about 28 times less than that of PEI. At the same time the inhibitory efficiency of the other tested polycation (PDMAEM) is zero. Therefore the established strong PEI inhibitory efficiency could not be explained by the positive charged amino groups in the side chains of the PEI macromolecule. It is known that PEI macromolecules are usualy branched ones and depending on the degree of branching, the ratious between the primary, secondary and tertiary aminogroups in its macromolecules are between $1: 1: 1$ and $1: 2: 1 .^{6}$ Probably, this PEI effect is a result of the proved ${ }^{6,7}$ polychelatogene PEI activity, due to the convenient macromolecular conformation and the presence of the different type aminogroups in the macromolecules of the commercial PEI with a branched structure. The relatively large hydrocarbon fragments in the side chains of the PDMAEM macromolecules may be a dominant unfavorable factor for a such polychelatogene activity.

The considerable PEI retardation effect on the $\mathrm{CO}$ nucleation at relatively low supersaturation $(S=1.3)$ is the reason to verify this PEI ability at higher $S$ values. $\tau$ and $\gamma$ values at $S=2.9$ and the temperatures choosen already $\left(25^{\circ} \mathrm{C}, 37^{\circ} \mathrm{C}\right.$, and $\left.50^{\circ} \mathrm{C}\right)$ are presented in Table II. These data indicate the PEI retardation effect on the $\mathrm{CO}$ nucleation at this high supersaturation also. It is important that this effect is the most strong at the physiological temperature as that at the lower $S$ values.

Table I. Effect of the temperature and the types of the water soluble polymers on the induction period $(\tau)$ and inhibitory efficiency $(\gamma)$

(Polymer concentration, $0.1 \%$; w/v, supersaturation, 1.3.)

\begin{tabular}{|c|c|c|c|}
\hline \multirow{2}{*}{ Polymer } & \multicolumn{3}{|c|}{$T /{ }^{\circ} \mathrm{C}$} \\
\hline & $\begin{array}{c}25 \\
\tau / \min (\gamma)\end{array}$ & $\begin{array}{c}37 \\
\tau / \min (\gamma)\end{array}$ & $\begin{array}{c}50 \\
\tau / \min (\gamma)\end{array}$ \\
\hline No & 25.0 & 11.0 & 4.0 \\
\hline PVP $^{5}$ & $63.5(1.54)$ & $29.5(1.68)$ & $4.0(0.00)$ \\
\hline CP $-46^{5}$ & $74.0(1.96)$ & $55.5(4.04)$ & $38.4(8.60)$ \\
\hline PDMAEM & $25.7(0.03)$ & $11.4(0.04)$ & $4.1(0.02)$ \\
\hline PEI & $1850(73.0)$ & $3450(312.6)$ & $980(244.0)$ \\
\hline
\end{tabular}


Table II. Effect of the temperature and the PEI concentration $\left(C_{\text {PEI }}\right)$ on the induction period $(\tau)$ and inhibitory efficiency $(\gamma)$ (Supersaturation, 2.9.)

\begin{tabular}{lllll}
\hline & \multicolumn{5}{c}{$C_{\mathrm{PEI}} / \%(\mathrm{w} / \mathrm{v})$} \\
\cline { 2 - 5 }$T /{ }^{\circ} \mathrm{C}$ & 0.00 & 0.03 & 0.07 & \multicolumn{1}{c}{0.10} \\
\cline { 2 - 5 } & \multicolumn{5}{c}{$\tau / \min (\gamma)$} \\
\hline & \multicolumn{5}{c}{$43.5(4.12)$} & $52.5(5.17)$ \\
37 & 2.5 & $55.5(21.20)$ & $75.0(29.00)$ & $310.0(123.00)$ \\
50 & 0.8 & $10.8(12.50)$ & $12.4(14.50)$ & $47.0(57.75)$ \\
& & & &
\end{tabular}

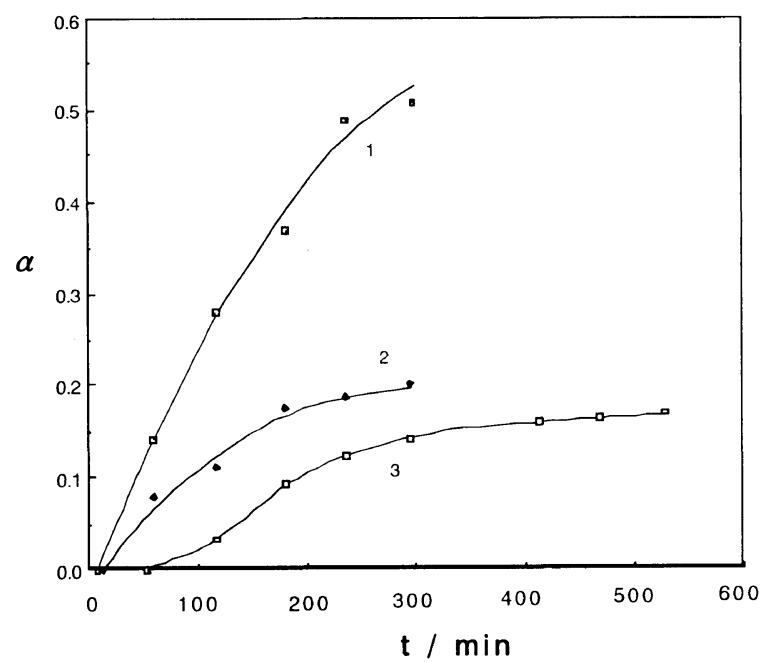

Figure 1. $\mathrm{CO}$ crystallization kinetics at $25^{\circ} \mathrm{C}$ without (curve 1) and with PEI: $C_{\mathrm{PEI}}=0.03 \%$ (curve 2) and $0.10 \%$ (curve 3). Supersaturation, 2.9 .

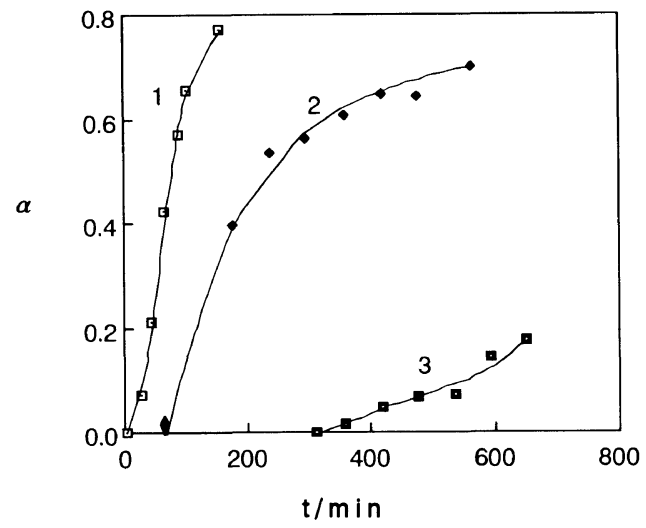

Figure 2. $\mathrm{CO}$ crystallization kinetics at $37^{\circ} \mathrm{C}$ without (curve 1) and with PEI: $C_{\mathrm{PEI}}=0.03 \%$ (curve 2 ) and $0.10 \%$ (curve 3 ). Supersaturation, 2.9 .

Besides the retardation effect on the $\mathrm{CO}$ nucleation, PEI decreases the crystal growth rate also (Figures 1-3). The higher PEI concentration, the more considerable crystal growth rate decrease is followed from the curves presented on these figures. The temperature is an effective parameter again.

The average sizes of the $\mathrm{CO}$ crystallites prodused at different temperatures in the absence and in the presence of $0.1 \%$ PEI are presented in Table III. Clearly they decrease 2-3 times on an average in the presence of PEI. This fact also proves that the PEI is an effective

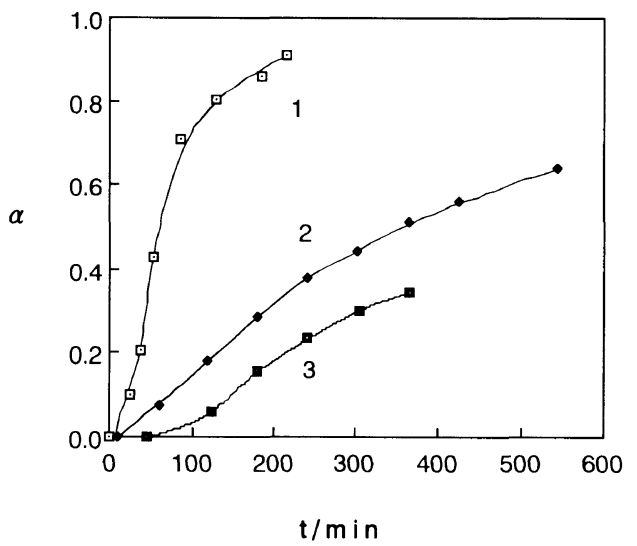

Figure 3. $\mathrm{CO}$ crystallization kinetics at $50^{\circ} \mathrm{C}$ without (curve 1) and with PEI: $C_{\mathrm{PEI}}=0.03 \%$ (curve 2 ) and $0.10 \%$ (curve 3 ). Supersaturation, 2.9 .

Table III. Effect of PEI on the average crystallite size $\left(d_{\mathrm{av}}\right)$ and on the ratio $(\rho)$ of $d_{\text {av }}$ to the same of the control crystallites produced under the similar conditions but without PEI Supersaturation, 2.9 .

\begin{tabular}{cccc}
\hline & \multicolumn{3}{c}{$d_{\mathrm{av}} / \mu \mathrm{m}$} \\
$T /{ }^{\circ} \mathrm{C}$ & Without PEI & With $0.1 \%(\mathrm{w} / \mathrm{v}) \mathrm{PEI}$ & \\
\cline { 2 - 3 } & & & \\
\hline 25 & 5.39 & 2.57 & 2.10 \\
37 & 8.94 & 3.24 & 2.76 \\
50 & 5.47 & 2.46 & 2.22 \\
\hline
\end{tabular}

dispersing agent for the $\mathrm{CO}$ crystallization also. This effect of the PEI on the CO crystallization is as the other ones the most notable at $37^{\circ} \mathrm{C}$ when the average size of $\mathrm{CO}$ crystallytes is maximum. Therefore, PEI has the both inhibitory effect on the $\mathrm{CO}$ nucleation, crystal growth rate and on the crystallite aggregation.

\section{CONCLUSION}

It is proved that in contrast to PDMAEM, PEI has the most significant inhibitory effect on the CO crystallization among the polymer inhibitors tested up to now. This inhibition effect is complex; on the $\mathrm{CO}$ nucleation, crystal growth rate and on the crystallite aggregation. This complex effect could be probably control by the chemical modification ${ }^{8}$ of PEI.

\section{REFERENCES}

1. T. E. Crowfold, E. P. Crematy, and A. E. Alexander, Australian J. Chem., 21, 1067 (1968).

2. S. Sarig, F. Kahaha, Y. Fichs, N. Karasikov, and R. Azoury, J. Crystal. Growth, 87, 431 (1988).

3. R. Azoury, A. Roudolph, and G. Drach, J. Crystal. Growth, 64, 389 (1989).

4. R. Ziller and H. Ruppecht, Drug. Develop. Ind. Pharm., 14, 2341 (1988).

5. G. S. Georgiev, M. D. Djarova, J. I. Petkova, G. I. Georgiev, and N. S. Koseva, Polym. J., 27, 441 (1995).

6. B. L. Rivas and K. E. Ceckeler, Adv. Polym. Sci., 102, 171 (1992).

7. B. Ya. Spivakov, K. E. Geckeler, and E. Bayer, Nature, 315, 313 (1985).

8. B. L. Rivas, H. A. Maturana, R. E. Gatalan, and I. M. Perich, J. Appl. Polym. Sci., 38, 801 (1989). 